\title{
A multicriteria decision analysis (MCDA) applied to three long-term prophylactic treatments for hereditary angioedema in Spain
}

\author{
Néboa Zozaya ${ }^{1}$, Teresa Caballero ${ }^{2,3}$, Teresa González-Quevedo4, Pedro Gamboa Setien ${ }^{5}$, Ma Ángeles González \\ Ramón Jódar7, José Luis Poveda-Andrés ${ }^{8}$, Encarna Guillén-Navarro', Agustín Rivero Cuadrado ${ }^{10}$, Álvaro Hidalgo-Vega ${ }^{11,12}$ \\ ${ }^{1}$ Weber, Madrid - Spain \\ ${ }^{2}$ Servicio de Alergología, Hospital Universitario La Paz; Hospital La Paz Institute for Health Research (IdiPaz), Madrid - Spain \\ ${ }^{3}$ Center for Biomedical Research Network on Rare Diseases (CIBERER U754), Madrid - Spain \\ ${ }^{4}$ Unidad de Referencia de Angioedema para Andalucía, Unidad de Alergología, Hospital Universitario Virgen del Rocío, Sevilla - Spain \\ ${ }^{5}$ Unidad de Alergología, Hospital Universitario de Cruces, Bizcaia - Spain \\ ${ }^{6}$ Servicio de Farmacia, Hospital Universitario La Paz, Madrid - Spain \\ ${ }^{7}$ Servicio de Farmacia, Hospital Universitario Bellvitge, Barcelona - Spain \\ ${ }^{8}$ Servicio de Farmacia Hospitalaria, Hospital Universitari y Politècnic la Fe, Valencia - Spain \\ ${ }^{9}$ Sección de Genética Médica, Servicio de Pediadría, Hospital Clínico Universitario Virgen de la Arrixaca, IMIB-Arrixaca Universidad de Murcia, \\ CIBERER-ISCIII, Murcia - Spain \\ ${ }^{10}$ Hospital Universitario La Paz, Madrid - Spain \\ ${ }^{11}$ Fundación Weber, Madrid - Spain \\ ${ }^{12}$ Universidad de Castilla-La Mancha, Toledo - Spain
}

\begin{abstract}
Introduction: Hereditary angioedema (HAE) is a rare genetic disease that impairs quality of life and could be life-threatening. The aim of this study was to apply a multicriteria decision analysis to assess the value of three long-term prophylactic (LTP) therapies for HAE in Spain.

Methods: A multidisciplinary committee of 10 experts assessed the value of lanadelumab (subcutaneous use), C1-inhibitor (C1-INH; intravenous), and danazol (orally), using placebo as comparator. We followed the EVIDEM methodology that considers a set of 13 quantitative criteria. The overall estimated value of each intervention was obtained combining the weighting of each criterion with the scoring of each intervention in each criterion. We used two alternative weighting methods: hierarchical point allocation (HPA) and direct rating scale (DRS). A reevaluation of weightings and scores was performed.

Results: Lanadelumab obtained higher mean scores than C1-INH and danazol in all criteria, except for the cost of the intervention and clinical practice guidelines. Under the HPA method, the estimated values were $0.51(95 \%$ confidence interval [Cl]: 0.44-0.58) for lanadelumab, 0.47 (95\% Cl: $0.41-0.53)$ for $\mathrm{C} 1-\mathrm{INH}$, and $0.31(95 \% \mathrm{Cl}$ : $0.24-$ $0.39)$ for danazol. Similar results were obtained with the DRS method: $0.51(95 \% \mathrm{Cl}: 0.42-0.60), 0.47(95 \% \mathrm{Cl}$ : $0.40-0.54)$, and 0.27 (95\% Cl: $0.18-0.37$ ), respectively. The comparative cost of the intervention was the only criterion that contributed negatively to the values of lanadelumab and C1-INH. For danazol, four criteria contributed negatively, mainly comparative safety.

Conclusion: Lanadelumab was assessed as a high-value intervention, better than C1-INH and substantially better than danazol for LTP treatment of HAE.

Keywords: Drugs evaluation, Hereditary angioedema, Lanadelumab, Multicriteria decision analysis (MCDA), Rare disease
\end{abstract}

Received: August 24, 2021

Accepted: December 15, 2021

Published online: January 25, 2022

Corresponding author:

Néboa Zozaya

Calle Moreto, 17, 5 Dcha

28014, Madrid - Spain

neboa.zozaya@weber.org.es

\section{Introduction}

Health systems are faced with an increasing challenge associated with the funding of new and often high-cost medicines in a timely manner (1). There is increasing recognition that conventional appraisal approaches may be unsuitable for assessing the value of rare disease treatments (2). The inherent characteristics of rare diseases include scarcity of 
knowledge on the natural history of the disease, clinical trials limited by small heterogeneous populations, poor scientific background, little consensus in the endpoints of clinical trials, and uncertainty in cost-effectiveness estimates $(3,4)$.

Given their peculiarities, orphan drugs often fail to meet the cost-effectiveness thresholds established by health technology agencies; hence, there is a debate on whether traditional assessment methods are still appropriate for these products, as they do not consider any criteria other than efficacy, safety, and cost $(5,6)$. Thus, assessment of the value of a drug targeted for a rare disease's treatment should be more holistic, requiring a broader perspective that covers the patient, healthcare system, and societal levels, as well as a wider criteria framework (7-9).

The multicriteria decision analysis (MCDA) is an increasingly used tool that could help in providing a structured, multidimensional, and transparent approach to the evaluation of drugs (10). By explicitly considering a wide range of factors and the contribution of each one of them to the decision-making process, it can be particularly useful for the evaluation of drugs targeted for rare diseases, as a complement to standard economic evaluations and budget impact analyses $(9,10)$.

The multiplicity of issues, including uncertainty and ethical dilemmas, involved in appraising interventions for lowprevalence diseases suggest that MCDA, based on a holistic definition of value, is uniquely suited for decision-making (11). A reflective MCDA methodology that promotes the sharing of diverse perspectives could be useful to incorporate the vision of the different actors involved and to enhance the predictability of the process (12-14).

Hereditary angioedema (HAE) is a lifelong, rare, genetic, debilitating, and life-threatening disease characterized by unpredictable, acute, and recurrent episodes of edema (15). HAE has a significant impact on the lives of patients, both physically and emotionally, affecting their daily activities, work, and school life (16-18). There are several therapies approved by the European Medicines Agency (EMA) for HAE, none of them being curative. The goal of the treatment is to minimize the burden of the disease on patients and to ensure that they can live a life as close as possible to normal (19-21). The aim of long-term prophylactic (LTP) treatment or maintenance treatment is to prevent angioedema attacks from occurring or, at least, to reduce their frequency and severity.

The purpose of this study was to apply a MCDA to assess the value of three LTP therapies for HAE in the Spanish context, from a broad perspective. Specifically, we aimed to assess the value of danazol (the most commonly used standard treatment to date), plasma-derived C1-inhibitor (C1-INH) (Cinryze ${ }^{\circledR}$ ) (substitution treatment), and lanadelumab (a new treatment, the only LTP C1-INH approved by EMA at the time of the study). This assessment can provide useful information that could help to make better decisions about the use of any of these three interventions.

\section{Methods}

\section{Study design}

The current study assessed the value of the three LTP treatments available for $\mathrm{HAE}$, using placebo as comparator for each of them: lanadelumab (subcutaneous administration), C1-INH (intravenous), and danazol (oral). It was designed following published good methodological practices $(22,23)$ on the field-tested Evidence and Value: Impact on DecisionMaking (EVIDEM) framework (version 4.0) (24). The EVIDEM framework stimulates structured reflection from stakeholders through a set of 13 quantitative criteria grouped into five domains (CORE Model), regarding the need for intervention (three criteria), the comparative outcomes of the intervention (three criteria), the type of benefit of the intervention (two criteria), the economic consequences of the intervention (three criteria), and the knowledge about the intervention (two criteria).

\section{Panel design and training}

In order to gather insights from a broad range of perspectives, a multidisciplinary panel of 10 experts was invited to participate in a face-to-face MCDA session held in March 2019 in Madrid. Experts were chosen according to their professional profile and experience in the management of $\mathrm{HAE}$, trying to achieve a balanced geographical representation (six different Spanish Autonomous Communities were represented). Experts comprised three allergists, three hospital pharmacists, one national and one regional ex-payer, and two representatives of the Spanish Hereditary Angioedema Association. The session was chaired by the consultancy firm WEBER (Madrid, Spain). WEBER was responsible for training this group of experts on MCDA, explaining them in detail the methodology and its interpretation, and providing examples.

\section{Evidence matrix}

A comprehensive literature review was conducted by WEBER to retrieve relevant information for each of the 13 EVIDEM criteria assessed. The available evidence was used to develop an evidence matrix regarding the burden of the disease, its current epidemiology and management in Spain, and the three assessed drugs (summarized in Tab. I). Evidence was obtained from major biomedical literature databases (PubMed/Medline), clinical trial registries, published hospital evaluation reports, clinical practice guidelines (CPGs), and official European and Spanish healthcare evaluation bodies' webpages.

Clinical, safety, and patient-reported outcomes (PROs) evidence for the assessed drugs was obtained from all active controlled randomized clinical trials, observational studies, and product monograph (Summary of Product Characteristics, European Public Assessment Reports) available. Evidence was organized in a descriptive, summarized, and structured way. It was reviewed and validated by the three committee's allergists. The final version of this summary of relevant literature (evidence matrix), which was later shared with the whole experts' panel members during the presential meeting held, comprised a total of 190 bibliographic references.

\section{Criteria weighting and scoring}

Weights represent the trade-off between criteria and thus reveal which aspects of the three compared treatments were 
the most valued by each panelist. During the session, committee members were instructed to assign weights to each of the 13 criteria of the MCDA model, to explicit their individual perspective on their relative importance, done independently from the assessed interventions. A direct rating scale was used where each participant gave a relative weight per criterion using a nonhierarchical simple 5-point scale (1 = lowest relative importance, $5=$ highest relative importance) (22).

To appraise the interventions, committee members were instructed to score each criterion individually, based on the evidence matrix and their own experience and perception. Each expert assigned a score to each of the 13 criteria for the three interventions evaluated. Some of the criteria are defined by EVIDEM as absolute (i.e., severity of the disease), while others are defined as relative, as they are used to compare different alternatives (i.e., effectiveness). The scores ranged from 0 to 5 when the criterion was absolute, and from -5 to 5 when it was relative to a comparator. At the time of this study, we did not identify any head-to-head or indirect comparisons of any of the assessed drugs. For this reason, the comparators adopted were those used in the pivotal clinical trials of the respective interventions (placebo).

\section{Data analysis}

The overall MCDA estimated value of each drug was obtained by means of an additive linear model that combined all criteria value contributions. The value contribution of each criterion was calculated as the product of its individual normalized weight and score of each intervention in each criterion. The maximum possible overall value was +1 and the minimum -1. In particular, the following formula was used:

$$
V=\sum_{x=1}^{n} V_{x}=\sum_{x=1}^{n}\left(\frac{w_{x}}{\Sigma W_{n}} S_{x}\right)
$$

where $V$ is the total estimated value, $V_{x}$ the value contribution of the criterion $x, W_{x}$ the weighting of the criterion $x$, $\sum W_{n}$ the sum of all weights, and $S$ the normalized scoring of criterion $x$ (in a scale from -1 to 1 , by dividing the score by 5 , which is the maximum possible value).

\section{Scenario analysis}

An alternative weighting method (100 points allocation) was applied to test whether the total estimated values of the assessed drugs would change under a different preference elicitation approach. Each panelist distributed 100 points between the five domains of the framework, according to their relative importance (the greater the importance, the more points), and then distributed 100 points between the criteria included in each domain. Normalized weights were obtained.

To address structural uncertainty, a scenario analysis was also conducted to better understand whether the results from the MCDA exercise would differ by using a different set of criteria. This is done in accordance with the EVIDEM methodology, which suggests a flexible and adaptive approach to the context of decision-making $(22,24)$. In this scenario analysis, the criterion "Expert consensus/clinical practice guidelines" was omitted, under the basis that it may penalize innovative treatments that have not yet been included in the CPGs for timing reasons.

\section{Results}

Participants assigned the highest weight to disease severity, with the greatest consensus (4.50 points \pm 0.71 standard deviation [SD]), followed by comparative safety/tolerability, type of therapeutic benefit, and quality of evidence (4.10 points $\pm[0.74-0.88])$. The lowest mean weights were assigned to expert consensus/clinical practice guidelines and size of affected population, both with 2.80 points. The greatest variability in the range of responses occurred in the size of affected population (SD: 1.40), followed by unmet needs (SD: 1.20) (Fig. 1).

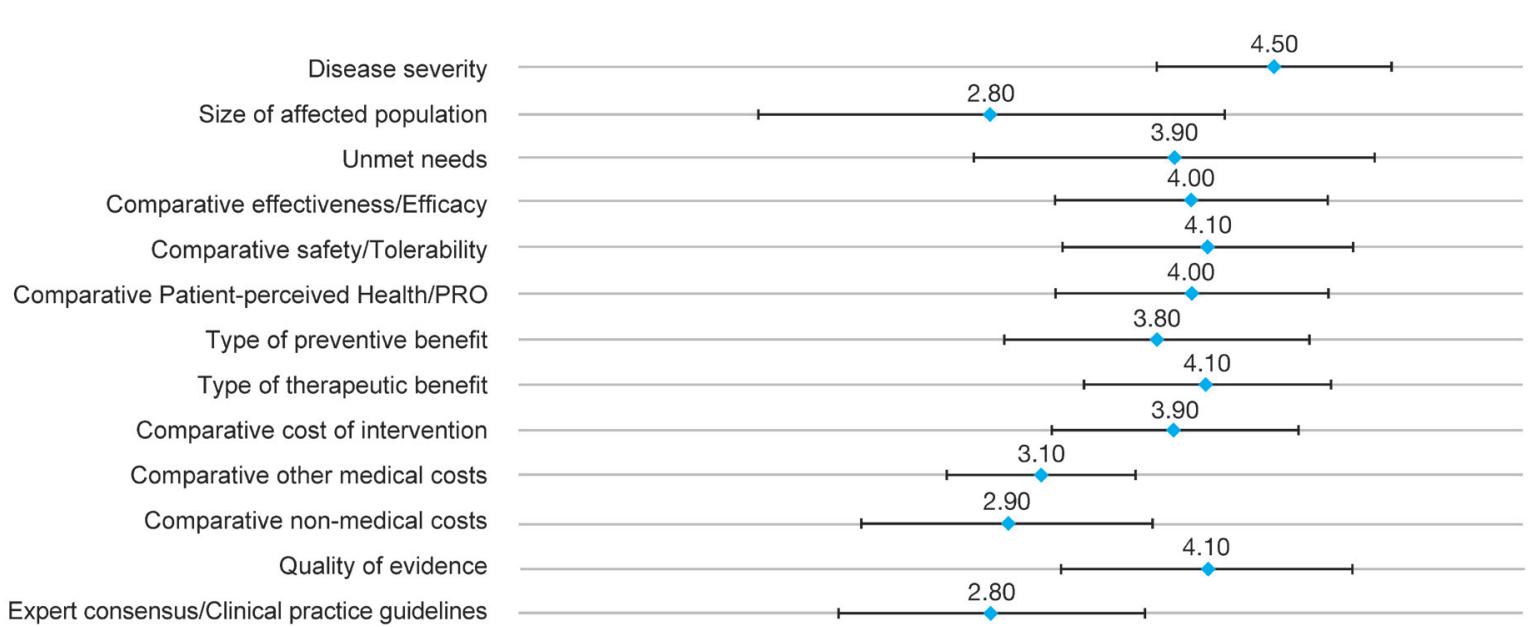

Min $\quad$ Max

$3.00 \quad 5.00$

$1.00 \quad 5.00$

$1.00 \quad 5.00$

$3.00 \quad 5.00$

$3.00 \quad 5.00$

$3.00 \quad 5.00$

$2.00 \quad 5.00$

$3.00 \quad 5.00$

$3.00 \quad 5.00$

$2.00 \quad 4.00$

$2.00 \quad 4.00$

$3.00 \quad 5.00$

$1.00 \quad 4.00$

Fig. 1 - Results of panelists' weights in the multicriteria decision analysis. PRO: patient-reported outcome. Mean weights are used. 


\section{Scoring of interventions}

Lanadelumab obtained higher mean scores than the C1-INH and danazol in all criteria, except for the cost of the intervention and CPG (Fig. 2). Efficacy obtained the highest mean score with a high degree of consensus (4.10 points \pm 0.57 ), followed by type of preventive benefit ( 3.95 points \pm $0.50)$. Lanadelumab was perceived as a valuable drug in terms of patient's quality of life (mean scores for the PRO criterion: 3.80 points \pm 0.79 ). The comparative cost of the intervention was the only criterion where lanadelumab obtained a negative average score $(-3.8 \pm 0.92)$, considering an average cost per patient of $€ 224,000$ in the first year of treatment and $€ 194,000$ in the following years. At the time of the study, the approval of a marketing and reimbursing price for lanadelumab had not been yet established in Spain, so a hypothetical price was used based on proprietary data supplied by the manufacturer. The other two cost criteria were scored positively: other healthcare costs $(2.85 \pm 1.42)$ and non-healthcare costs (3.55 \pm 0.69 ), representing a belief that the implementation of this drug generates an offset effect. The quality of the evidence supporting lanadelumab was perceived as very good by panelists $(3.60 \pm 0.70)$. By contrast, CPG was scored close to 0 , representing the fact that CPGs had not been updated with the latest innovation therapies and therefore did not include lanadelumab at the time of the study. The greatest variability occurred in the comparative safety profile (SD: 2.67).

For the $\mathrm{C} 1-\mathrm{INH}$, efficacy was the criterion with the highest mean score, with a high degree of consensus (3.50 points \pm 0.53 ), followed by CPGs (3.40 points \pm 1.17 ) (CPGs place C1-INH as first-line treatment). The only criterion with a negative score was also the comparative cost of the intervention vs. placebo ( $-2.50 \pm 0.97)$, considering an average annual cost per patient of between $€ 112,000$ and $€ 148,000$. The other two cost criteria were scored positively. The greatest variability also occurred in the comparative safety profile (SD: 2.69), while the highest consensus was found in quality of the evidence (SD: 0.42).

For danazol, the highest score was also given to the efficacy criterion ( 3.0 points \pm 1.33 ). The panelists emphasized that danazol is only effective in some subgroups of patients whose disease can be controlled by low doses of the drug. Four of the criteria were negatively scored vs. placebo: safety, comparative cost of intervention, other medical costs, and nonmedical costs. The lowest score was given to the comparative safety profile of danazol vs. placebo, with a high consensus $(-3.50 \pm 0.71)$. It was linked with the frequent adverse effects associated with danazol (25-27). The intervention cost was scored close to $0(-0.60 \pm 0.70)$, due to the low annual cost of this oral treatment (about $€ 70$ per patient annually in Spain). By contrast, other medical costs were scored negatively with a large variability $(-1.10 \pm 2.69)$, because of potential increases in hospitalizations, medical visits, etc., due to the lower control of the disease and the poor safety profile of danazol.

\section{Overall total value}

Lanadelumab obtained a mean total value estimate of 0.506 points (95\% Cl: $0.437-0.576)$, which was higher than the value obtained by C1-INH (0.466 [95\% Cl: $0.408-0.523])$ and much higher than the one obtained by danazol $(0.272$ [95\% Cl: 0.187-0.356]) (Fig. 3).

Differences among stakeholders were observed. Patients were the group who valued lanadelumab the highest $(0.591$ points), followed by physicians ( 0.523 points), while pharmacists were the group who valued it the lowest $(0.448)$. The greatest consensus was found among patients and physicians (SD: 0.023 and SD: 0.036, respectively), showing the patient and clinical perceived benefit of lanadelumab. By contrast, the lowest consensus was obtained for hospital pharmacists (SD: 0.202).

\section{Scenario analysis}

In the first scenario analyses, the use of an alternative weighting method (100 points allocation) resulted in changes of $0.5 \%$ in the overall value estimates for lanadelumab $(0.509$ in the alternative method vs. 0.506 in the base case scenario); $1.6 \%$ in the value for the C1-INH (0.473 vs. 0.466$)$ and $14.9 \%$ in the value for danazol ( 0.312 vs. 0.272$)$. The main explanation for those changes is given by the difference of weights provided for disease severity (13\% on the alternative method vs. $9 \%$ on the base case), comparative patient-perceived

Disease severity
Expert consensus/Clinical practice guidelines
Comparative Patient-perceived Health/PRO
Type of preventive benefit
Type of therapentic benefit
Comparative cost of intervention
Comparative other medical costs
Comparative non-medical costs

Fig. 2 - Mean scores of each intervention.

C1-INH: C1-inhibitor; PRO: patient-reported outcome. 


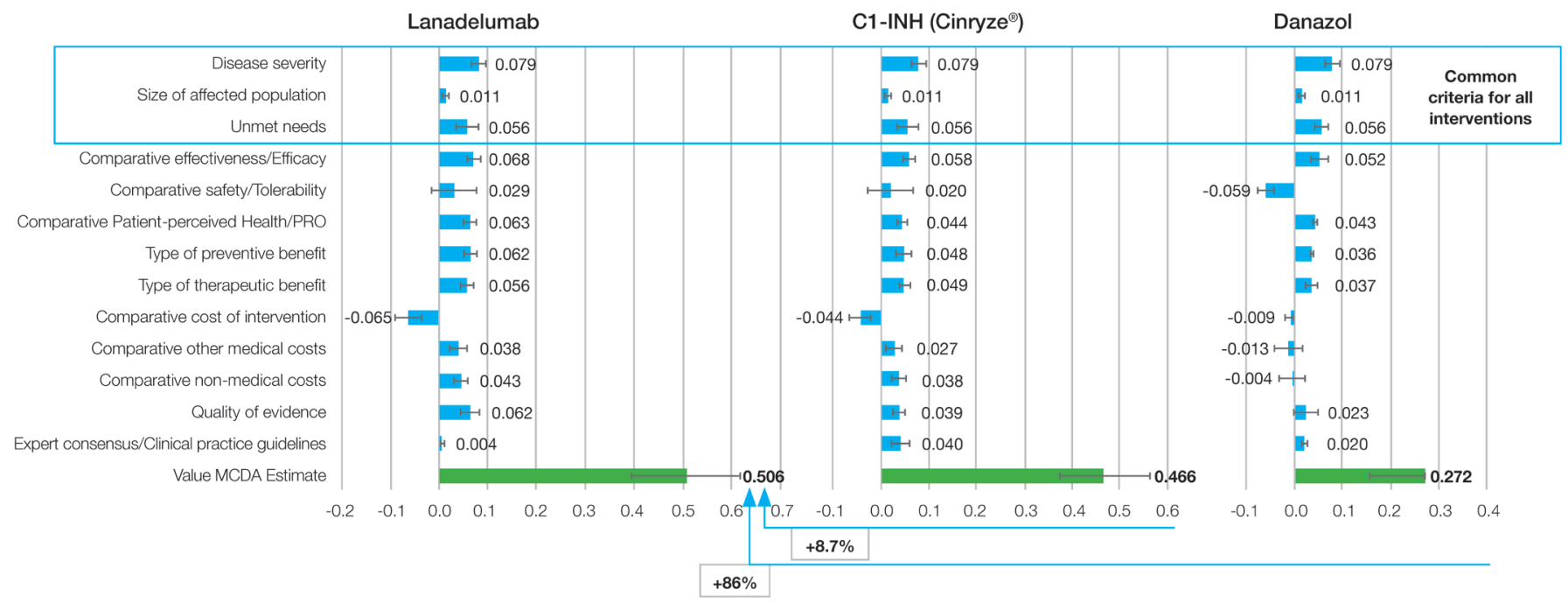

Fig. 3 - Mean value contribution of each intervention.

C1-INH: C1-inhibitor; MCDA: multicriteria decision analysis; PRO: patient-reported outcome.

health/PRO (6\% vs. $8 \%)$ and comparative nonmedical costs $(4 \%$ vs. $6 \%)$.

The second scenario analysis consisted of the exclusion of the GPC criterion from the base case criteria set. This was done as, at the time of the meeting, lanadelumab was not yet included in any GPC, given Food and Drug Administration (FDA) approval had not been obtained. This change resulted in an increase of the mean value estimated for lanadelumab (0.533 vs. 0.506) and a decrease for the C1-INH (0.451 vs. 0.466 ) and danazol (0.267 vs. 0.272 ).

\section{Discussion}

To our knowledge, this is the first MCDA applied to three treatments with different routes of administration for a rare disease. The results suggest that lanadelumab, a new prophylactic treatment for $\mathrm{HAE}$, is perceived as a high-value intervention (0.51 points), better than the $\mathrm{C} 1-\mathrm{INH}$ ( 0.47 points) and substantially better than danazol ( 0.27 points).

The estimated values of lanadelumab and the C1-INH were similar or slightly above the values obtained for other innovative drugs to which the MCDA-EVIDEM framework was applied (between 0.33 and 0.51) $(11,14,28-32)$. However, the value estimates in this study are not intended to be used in a prescriptive manner, and the valuation obtained is neither generalizable to other comparators nor lasting over time.

Disease severity, quality of evidence, and type of therapeutic benefit were the highest-ranked criteria for panelists. However, we observed notable differences between different types of stakeholders (in weighting, scoring, and understanding of the methodology). Although the study did not have the power to measure variations across categories of stakeholders, a subgroup analysis suggests that patient representatives tended to assign higher weights to disease severity than other panelists and lower weights to comparative costs, and this highlights the importance of applying a multidisciplinary perspective to this context.
The comparative cost of the intervention was the only criterion where lanadelumab obtained a negative average score. The other two cost criteria were scored positively, suggesting that the treatment could produce savings on other healthcare costs and non-healthcare costs. The latter may be associated with the potential reduction of working or teaching hours lost due to the better control of the disease and the more appropriate route of administration and posology. This highlights the need to assess the value from a holistic point of view that takes into account other related costs from a social perspective.

The literature about MCDA methodology suggests that it is increasingly being used in the context of appraising orphan drugs $(9,33)$. It has been field-tested and implemented in various real-world settings, including Spain, where the HTA body in Catalonia has explored its suitability to appraise orphan drugs $(12,34)$. We have used the EVIDEM methodology, an open-source, collaboratively developed MCDA framework designed to appraise the holistic value of healthcare interventions. It has been considered as a flexible approach with the potential to assist in decision-making about reimbursement for orphan drugs (9). However, according to some experts, further research regarding its application must be conducted (35).

This study has some limitations: (1) Inherent limitations of the EVIDEM approach: a fixed set of criteria which may exclude relevant criteria while considering nonrelevant criteria, such as CPGs. (2) The 10-member panel could be considered small to be regarded as representative at a national level. Nevertheless, the number of experts included is in line with that in other MCDA studies carried out for a specific intervention (8-19 experts) $(11,28,29)$. (3) The analysis involves some cognitive complexity, especially because several drugs were evaluated simultaneously. This has potentially led to response inconsistencies, detected during the meeting, which were corrected, yielding more consistent and reliable results. Inconsistencies have been also detected in 
TABLE I - Summary of the evidence matrix used for the assessment

\begin{tabular}{|c|c|c|c|c|}
\hline Domain & Criteria & Lanadelumab & C1-INH (human) & Danazol \\
\hline \multirow[b]{2}{*}{$\begin{array}{l}\text { Need for } \\
\text { intervention }\end{array}$} & $\begin{array}{l}\text { 1. Disease } \\
\text { severity }\end{array}$ & \multicolumn{3}{|c|}{$\begin{array}{l}\text { Clinical characteristics of the disease (attacks of swelling and laryngeal attacks). HAE can impair } \\
\text { patients' ability to perform daily activities and this effect becomes more pronounced as pain severity } \\
\text { increases. Psychological burden. }\end{array}$} \\
\hline & $\begin{array}{l}\text { 2. Size of } \\
\text { affected } \\
\text { population }\end{array}$ & \multicolumn{3}{|c|}{$\begin{array}{l}\text { Prevalence of HAE patients aged } 12 \text { years or older requiring long-term preventive treatment in Spain: } \\
\sim 0.95-1.74 / 100,000 \text { inhabitants (between } 392 \text { and } 720 \text { patients). }\end{array}$} \\
\hline \multirow{2}{*}{$\begin{array}{l}\text { Comparative } \\
\text { outcomes of } \\
\text { intervention }\end{array}$} & $\begin{array}{l}\text { 4. Comparative } \\
\text { effectiveness/ } \\
\text { efficacy }\end{array}$ & $\begin{array}{l}\text { HELP study: RCT. Reduction } \\
\text { of attacks ( } 73 \% \text { to } 87 \% \text { ) } \\
\text { compared with placebo, and } \\
\text { reduction of attack severity. }\end{array}$ & $\begin{array}{l}\text { Single-arm, open-label extension } \\
\text { study: decrease in monthly rate of HAE } \\
\text { attacks ( } 0.47 \text { vs. } 4.7 \text { attacks/month). }\end{array}$ & \\
\hline & $\begin{array}{l}\text { 6. Comparative } \\
\text { patient- } \\
\text { perceived } \\
\text { health/PRO }\end{array}$ & $\begin{array}{l}\text { Patients-improved HRQoL } \\
\text { (Angioedema Quality of Life } \\
\text { questionnaire). Subcutaneous } \\
\text { route. }\end{array}$ & $\begin{array}{l}\text { Improvement in HRQoL (SF-36 } \\
\text { scores). Intravenous route. }\end{array}$ & $\begin{array}{l}\text { Inferior in } \mathrm{HRQ} \text { oL to alternative } \\
\text { treatments such as } \mathrm{C} 1-\mathrm{INH} \text {. } \\
\text { Orally. }\end{array}$ \\
\hline \multirow{2}{*}{$\begin{array}{l}\text { Type of } \\
\text { benefit of } \\
\text { intervention }\end{array}$} & $\begin{array}{l}\text { 7. Type of } \\
\text { preventive } \\
\text { benefit }\end{array}$ & $\begin{array}{l}\text { More patients in the } \\
\text { lanadelumab treatment group } \\
\text { were attack-free than placebo } \\
\text { (39-44\% vs. } 2 \%) \text {. }\end{array}$ & $\begin{array}{l}\text { Extension study: significant reduction } \\
\text { in the frequency of attacks against } \\
\text { historical rates. }\end{array}$ & $\begin{array}{l}\text { Pivotal clinical trial and in } \\
\text { clinical practice: danazol } \\
\text { is effective in reducing the } \\
\text { number of HAE attacks. }\end{array}$ \\
\hline & $\begin{array}{l}\text { 8. Type of } \\
\text { therapeutic } \\
\text { benefit }\end{array}$ & $\begin{array}{l}\text { Lanadelumab does not cure } \\
\text { HAE, but reduces the severity } \\
\text { and frequency of HAE attacks. }\end{array}$ & $\begin{array}{l}\text { C1-INH does not cure HAE, but reduces } \\
\text { the severity and frequency of HAE } \\
\text { attacks. }\end{array}$ & $\begin{array}{l}\text { Danazol does not cure HAE, but } \\
\text { reduces the proportion of HAE } \\
\text { attacks. }\end{array}$ \\
\hline \multirow{4}{*}{$\begin{array}{l}\text { Economic } \\
\text { consequences } \\
\text { of intervention }\end{array}$} & \multirow{2}{*}{$\begin{array}{l}\text { 10. Comparative } \\
\text { other medical } \\
\text { costs }\end{array}$} & \multicolumn{3}{|c|}{$\begin{array}{l}\text { HAE attacks can require emergency care or hospitalization, imposing a costly burden on health systems. } \\
\text { The health cost of the patient with HAE depends on the severity of the attacks (a severe attack costs } 20 \\
\text { times more than a mild attack, and a moderate attack three times more than a mild attack). }\end{array}$} \\
\hline & & $\begin{array}{l}\text { Lanadelumab reduced the } \\
\text { number of moderate or } \\
\text { serious attacks by between } \\
70 \% \text { and } 83 \% \text { vs. placebo. }\end{array}$ & $\begin{array}{l}\text { C1-INH reduced the number of serious } \\
\text { attacks by } 32 \% \text { vs. placebo. }\end{array}$ & $\begin{array}{l}\text { The long-term use of danazol } \\
\text { is associated with important } \\
\text { adverse events. }\end{array}$ \\
\hline & 11. Comparative & \multicolumn{3}{|c|}{$\begin{array}{l}\text { The indirect cost for acute attacks was estimated at } € 11.2 \text { when the treatment was subcutaneous with } \\
\text { icatibant; } 43 \% \text { of the indirect cost was due to productivity losses. }\end{array}$} \\
\hline & $\begin{array}{l}\text { nonmedical } \\
\text { costs }\end{array}$ & $\begin{array}{l}\text { Lanadelumab trials: more } \\
\text { attack-free days per month } \\
\text { than placebo ( } 21 \% \text { more). }\end{array}$ & $\begin{array}{l}\text { C1-INH trials: days without swelling } \\
\text { were } 10 \text { vs. } 30 \text { with placebo. } \\
\text { (Attack-free days were not analyzed). }\end{array}$ & $\begin{array}{l}\text { Work/school absence: } 24 \text { days/ } \\
\text { year with danazol, and } 0 \text { days/ } \\
\text { year with } \mathrm{C} 1 \text { inhibitor. }\end{array}$ \\
\hline \multirow[b]{2}{*}{$\begin{array}{l}\text { Knowledge } \\
\text { about } \\
\text { intervention }\end{array}$} & $\begin{array}{l}\text { 12. Quality of } \\
\text { evidence }\end{array}$ & $\begin{array}{l}\text { HELP study: ICER Evidence } \\
\text { Report assigned a "promising } \\
\text { but inconclusive (P/I) rating." }\end{array}$ & $\begin{array}{l}\text { Pivotal trial for C1-INH: ICER Evidence } \\
\text { Report judged "to be of fair quality." }\end{array}$ & $\begin{array}{l}\text { Pivotal study of danazol: poor } \\
\text { quality of evidence. }\end{array}$ \\
\hline & $\begin{array}{l}\text { 13. Expert } \\
\text { consensus/ } \\
\text { clinical } \\
\text { practice } \\
\text { guidelines }\end{array}$ & $\begin{array}{l}\text { Clinical practice guidelines } \\
\text { still did not include it (at the } \\
\text { time of this exercise) }\end{array}$ & $\begin{array}{l}\text { WAO recommends plasma-derived } \\
\text { C1-INH for long-term prophylaxis as a } \\
\text { first-line use. }\end{array}$ & $\begin{array}{l}\text { WAO suggests androgens for } \\
\text { second-line use, noting their } \\
\text { adverse androgenic and anabolic } \\
\text { effects, drug interactions, and } \\
\text { contraindications. }\end{array}$ \\
\hline
\end{tabular}

$\mathrm{C} 1-\mathrm{INH}=\mathrm{C} 1$-inhibitor; $\mathrm{HAE}=$ hereditary angioedema; $\mathrm{HRQOL}=$ health-related quality of life; ICER = Institute for Clinical and Economic Review; RCT = randomized controlled trial; $\mathrm{WAO}=$ World Allergy Organization . 
other MCDA studies $(22,36)$, which reinforces the importance of training experts on MCDA before carrying out the project. (4) At the time of the study, the availability of some pieces of evidence for the three treatments evaluated was limited. For certain aspects of the evaluation, lack of relevant or upto-date evidence (e.g., guidelines) may have affected the assessments. (5) We have not taken into account the qualitative criteria proposed by EVIDEM, which are much more subjective and complicated to score, but could help to better understand the ethical value of treatments. (6) We did not take into account the potential differences in the randomized controlled trial study samples.

\section{Conclusions}

The MCDA methodology allowed for a detailed analysis and discussion of the overall value of lanadelumab in HAE prophylactic treatment in a systematic, objective, and transparent way. The exercise also permitted a multidisciplinary group of Spanish patients, clinicians, and decision-makers to identify and express what matters to them in this scenario, considering a wide range of factors that may impact the decision. Lanadelumab was perceived as a highly valued intervention when compared with the $\mathrm{C} 1-\mathrm{INH}$ and danazol, in all evaluated criteria, except for its cost.

\section{Abbreviations (alphabetical order)}

AEMPS = Spanish Medicines Agency (Agencia Española de Medicamentos y Productos Sanitarios); C1-INH = C1-inhibitor; $\mathrm{CPG}=$ clinical practice guidelines; DRS = direct rating scale; EMA = European Medicines Agency; EVIDEM = Evidence and Value: Impact on Decision-Making; $\mathrm{HAE}=$ hereditary angioedema; HPA = hierarchical point allocation; $\mathrm{HRQ}$ oL $=$ healthrelated quality of life; LTP therapy = long-term prophylactic therapy; $\mathrm{MCDA}=$ multicriteria decision analysis; ORPH-VAL = European Working Group for Value Assessment and Funding Processes in Rare Diseases; PRO = patient-reported outcome; $\mathrm{RCT}$ = randomized controlled trial; $\mathrm{SD}$ = standard deviation.

\section{Disclosures}

Competing interests: TC has received grant research support and/or speaker/consultancy fees from BioCryst, CSL-Behring, Novartis, Octapharma, Pharming NV, and Takeda; has received funding to attend conferences/educational events from CSL Behring, Novartis, and Takeda; is/has been a clinical trial/registry investigator for Biocryst, CSL Behring, Novartis, Pharming NV, and Takeda and is a researcher from the IdiPaz program to promote research activities. EGN has received grant research support and/or speaker/consultancy fees and/ or scientific meeting coverage from Alnylam, Biomarin, Genzyme, Takeda, and UCB. PG has received speaker/consultancy fees from Takeda and Roxall. TGQ, MAG, RJ, JLPA, and ARC received funding from Takeda related to the hours dedicated to this project. NZ and $\mathrm{AH}$ work for Weber and Weber Foundation, consulting companies which have received funding from Takeda to develop this project. Funding: Takeda Pharmaceutical Company Limited funded the development of this study. The funding body had no role in the design of the study, collection, analysis, and interpretation of data, nor in writing the manuscript.

Author's contribution: $\mathbf{A H}$ and $\mathbf{N Z}$ have been responsible for the conceptualization and design of the work. TC, TGQ, PG, MAG, RJ, JLPA, EGN, ARC have generated the data. NZ has analyzed and interpreted the data, as well as developed the draft of this manuscript. All authors have reviewed and approved this manuscript.

Availability of data and material: The datasets used and analyzed during the current study are available from the corresponding author on reasonable request.

Ethics approval and consent to participate: Not applicable.

Consent for publication: Not applicable.

\section{References}

1. Godman B, Malmström RE, Diogene E, et al. Are new models needed to optimize the utilization of new medicines to sustain healthcare systems? Expert Rev Clin Pharmacol. 2015;8(1):77-94. CrossRef PubMed

2. Nicod E, Whittal A, Drummond M, Facey K. Are supplemental appraisal/reimbursement processes needed for rare disease treatments? An international comparison of country approaches. Orphanet J Rare Dis. 2020;15(1):189. CrossRef PubMed

3. Picavet E, Cassiman D, Hollak CE, Maertens JA, Simoens S. Clinical evidence for orphan medicinal products - a cause for concern? Orphanet J Rare Dis. 2013;8(1):164. CrossRef PubMed

4. Picavet E, Morel T, Cassiman D, Simoens S. Shining a light in the black box of orphan drug pricing. Orphanet J Rare Dis. 2014;9(1):62. CrossRef PubMed

5. Iskrov G, Miteva-Katrandzhieva T, Stefanov R. Multi-criteria decision analysis for assessment and appraisal of orphan drugs. Front Public Health [Internet]. 2016;4:214. [Accessed February 2017) CrossRef

6. Simoens S. Health technologies for rare diseases: does conventional HTA still apply? Expert Rev Pharmacoecon Outcomes Res. 2014;14(3):315-317. CrossRef PubMed

7. Annemans L, Aymé S, Le Cam Y, et al. Recommendations from the European Working Group for Value Assessment and Funding Processes in Rare Diseases (ORPH-VAL). Orphanet J Rare Dis. 2017;12:50. CrossRef

8. Schlander M, Garattini S, Kolominsky-Rabas $P$, et al. Determining the value of medical technologies to treat ultra-rare disorders: a consensus statement. J Mark Access Health Policy. 2016;4:33039. PubMed CrossRef

9. Badia X, Chugani D, Abad MR, et al. Development and validation of an MCDA framework for evaluation and decisionmaking of orphan drugs in Spain. Expert Opin Orphan Drugs. 2019;7(7-8):363-372. CrossRef

10. Drake JI, de Hart JCT, Monleón C, Toro W, Valentim J. Utilization of multiple-criteria decision analysis (MCDA) to support healthcare decision-making FIFARMA, 2016. J Mark Access Health Policy. 2017;5(1):1360545. CrossRef PubMed

11. Wagner $M$, Khoury $H$, Bennetts $L$, et al. Appraising the holistic value of lenvatinib for radio-iodine refractory differentiated thyroid cancer: a multi-country study applying pragmatic MCDA. BMC Cancer. 2017;17(1):272. CrossRef PubMed

12. Guarga $L$, Badia $X$, Obach $M$, et al. Implementing reflective multicriteria decision analysis (MCDA) to assess orphan drugs value in the Catalan Health Service (CatSalut). Orphanet J Rare Dis. 2019;14(1):157. CrossRef PubMed

13. Wagner M, Samaha D, Cuervo J, et al. Applying reflective multicriteria decision analysis (MCDA) to patient-clinician shared decision-making on the management of gastroenteropancreatic neuroendocrine tumors (GEP-NET) in the Spanish context. Adv Ther. 2018;35(8):1215-1231. CrossRef PubMed

14. Jiménez $A$, Ais $A$, Beaudet $A$, Gil $A$. Determining the value contribution of selexipag for the treatment of pulmonary arterial hypertension (PAH) in Spain using reflective multicriteria decision analysis (MCDA). Orphanet J Rare Dis. 2018;13:220. CrossRef PubMed 
15. Caballero Molina T, Pedrosa Delgado M, Gómez Traseira C. [Hereditary angioedema]. Med Clin (Barc). 2015;145(8): 356-365. CrossRef PubMed

16. Craig $\mathrm{T}$, Busse $\mathrm{P}, \mathrm{G}$ ower RG, et al. Long-term prophylaxis therapy in patients with hereditary angioedema with C1 inhibitor deficiency. Ann Allergy Asthma Immunol. 2018;121(6):673679. CrossRef PubMed

17. Lumry WR, Castaldo AJ, Vernon MK, Blaustein MB, Wilson DA, Horn PT. The humanistic burden of hereditary angioedema: impact on health-related quality of life, productivity, and depression. Allergy Asthma Proc. 2010;31(5):407-414. CrossRef PubMed

18. Aygören-Pürsün E, Bygum A, Beusterien K, et al. Socioeconomic burden of hereditary angioedema: results from the hereditary angioedema burden of illness study in Europe. Orphanet J Rare Dis. 2014;9(1):99. CrossRef PubMed

19. Agostoni A, Aygören-Pürsün E, Binkley KE, et al. Hereditary and acquired angioedema: problems and progress: proceedings of the third C1 esterase inhibitor deficiency workshop and beyond. J Allergy Clin Immunol. 2004;114(3 Suppl):S51-S131. CrossRef PubMed

20. Bowen T, Cicardi M, Bork K, et al. Hereditary angioedema: a current state-of-the-art review, VII: Canadian Hungarian 2007 International Consensus Algorithm for the Diagnosis, Therapy, and Management of Hereditary Angioedema. Ann Allergy Asthma Immunol. 2008;100(1 Suppl 2):S30-S40. CrossRef PubMed

21. Zeerleder S, Levi M. Hereditary and acquired C1-inhibitordependent angioedema: from pathophysiology to treatment. Ann Med. 2016;48(4):256-267. CrossRef PubMed

22. Thokala P, Devlin N, Marsh K, et al. Multiple criteria decision analysis for health care decision making - an introduction: report 1 of the ISPOR MCDA Emerging Good Practices Task Force. Value Health. 2016;19(1):1-13. CrossRef PubMed

23. Marsh K, IJzerman M, Thokala P, et al. Multiple criteria decision analysis for health care decision making - emerging good practices: Report 2 of the ISPOR MCDA Emerging Good Practices Task Force. Value Health. 2016;19(2):125-137. CrossRef PubMed

24. Goetghebeur MM, Wagner M, Khoury H, Levitt RJ, Erickson LJ, Rindress D. Bridging Health Technology Assessment (HTA) and Efficient Health Care Decision Making with Multicriteria Decision Analysis (MCDA): Applying the EVIDEM Framework to Medicines Appraisal. Med Decis Making. 2012;32(2):376-88. CrossRef PubMed

25. Maurer M, Magerl M, Ansotegui I, et al. The international WAO/EAACI guideline for the management of hereditary angioedema - the 2017 revision and update. Allergy. 2018;73(8):1575-1596. CrossRef PubMed

26. Bork K, Bygum A, Hardt J. Benefits and risks of danazol in hereditary angioedema: a long-term survey of 118 patients.
Ann Allergy Asthma Immunol. 2008;100(2):153-161. CrossRef PubMed

27. Betschel S, Badiou J, Binkley K, et al. Canadian hereditary angioedema guideline. Allergy Asthma Clin Immunol 2014;10(1):50. PubMed $\underline{\text { CrossRef }}$

28. Garau M, Hampson G, Devlin N, Mazzanti NA, Profico A. Applying a Multicriteria Decision Analysis (MCDA) approach to elicit stakeholders' preferences in Italy: The case of obinutuzumab for rituximab-refractory indolent non-Hodgkin lymphoma (iNHL). PharmacoEconom Open. 2018;2(2):153-163. CrossRef PubMed

29. Tony $M$, Wagner $M$, Khoury $H$, et al. Bridging health technology assessment (HTA) with multicriteria decision analyses (MCDA): field testing of the EVIDEM framework for coverage decisions by a public payer in Canada. BMC Health Serv Res. 2011;11(1):329. CrossRef PubMed

30. Goetghebeur $M M$, Wagner $M$, Khoury $H$, Rindress $D$, Grégoire J-P, Deal C. Combining multicriteria decision analysis, ethics and health technology assessment: applying the EVIDEM decision-making framework to growth hormone for Turner syndrome patients. Cost Eff Resour Alloc. 2010;8(1):4. CrossRef PubMed

31. Zozaya N, Martínez-Galdeano L, Alcalá B, et al. Determining the value of two biologic drugs for chronic inflammatory skin diseases: results of a multi-criteria decision analysis. BioDrugs. 2018;32(3):281-291. CrossRef PubMed

32. Álvarez-Román MT, Cuervo-Arango I, Pérez-Santamarina $\mathrm{R}$, et al. Determining the value contribution of emicizumab (Hemlibra ${ }^{\circledR}$ ) for the prophylaxis of haemophilia A with inhibitors in Spain by multi-criteria decision analysis. Glob Reg Health Technol Assess. 2019:1-8. CrossRef

33. Zozaya González, N, Oliva Moreno, J, Hidalgo Vega, A. MultiCriteria Decision Analysis in Healthcare: its usefulness and limitations for decision making [Internet]. Fundación Weber. Madrid (Spain): Fundación Weber; 2018. (Accessed August 2021) Online

34. Gilabert-Perramon A, Torrent-Farnell J, Catalan A, et al. Drug evaluation and decision making in Catalonia: development and validation of a methodological framework based on MultiCriteria Decision Analysis (MCDA) for orphan drugs. Int J Technol Assess Health Care. 2017;33(1):111-120. CrossRef PubMed

35. Friedmann $C$, Levy $P$, Hensel $P$, Hiligsmann $M$. Using multicriteria decision analysis to appraise orphan drugs: a systematic review. Expert Rev Pharmacoecon Outcomes Res. 2018;18(2):135-146. CrossRef PubMed

36. Angelis A, Kanavos P. Value-based assessment of new medical technologies: towards a robust methodological framework for the application of multiple criteria decision analysis in the context of health technology assessment. PharmacoEconomics. 2016;34(5):435-446. CrossRef PubMed 